\title{
MODELING AND OPTIMIZATION OF ALUMINUM FOAM CYLINDRICAL DOUBLE TUBES UNDER AXIAL IMPACT
}

\author{
F. Djamaluddin, S. Abdullah*, A.K. Arrifin and Z.M. Nopiah \\ Faculty of Engineering and Built Environment \\ Universiti Kebangsaan Malaysia \\ 43600 UKM Bangi, Selangor, Malaysia \\ *Email : shahrum@eng.ukm.my \\ Tel: +60-3-89118411, Fax: +60-3-89259659
}

\begin{abstract}
Due to their high energy absorption and lightweight material, foam-filled metallic tubes are used for vehicle structures to improve occupant safety and to reduce weight for fuel consumption efficiency. This paper presents the optimization of the empty and foamfilled double circular tubes under axial impact loading. In this work, both ends of a circular tube were clamped, at the bottom as a boundary condition and at the top to apply quasi-static force with respect to the longitudinal direction. The finite element model was validated with experimental tests taken from the literature. Finite element analysis and optimization design were combined to observe the crashworthiness of the double tubes. The geometric dimensions, such as the diameter and thickness of the tubes, were chosen as the design variables. The crush parameters, namely minimum peak crushing force and maximum specific energy absorption, were calculated using the non-dominated sorting genetic algorithm II to obtain the Pareto optimal solution. The radial basis function and factorial were calculated to formulate the objective and variable functions. The results show that aluminum foam-filled double circular tubes have more crashworthiness capability than empty tubes. The optimum values of the foam-filled tubes were higher than the empty double cylindrical tubes $(3.5 \%)$. Finally, foam-filled double circular tubes can be recommended as the energy absorber in automobiles.
\end{abstract}

Keywords: Aluminum foam; crashworthiness; circular tube; radial basis function; axial impact.

\section{INTRODUCTION}

Several researchers have studied the behavior of thin-walled tubes, considering the geometry, size, cross section and the loading condition of the tubes to improve energy absorption [1, 2]. For instance, the progressive buckling, inversion and splitting of circular tubes have been discussed previously [3]. Furthermore, the collapsible energy absorbers of different tube structures, i.e. circular and square tubes, have been explored [4] and it was found that the energy absorbing capability of circular tubes is better than that of square. To improve the crashworthiness capability of thin-walled tubes, some researchers [5-9] used cellular materials, such as foam. Similarly, empty and foam-filled circular tubes with a double-cell profile have also been studied [10,11]. Due to faster computers and better algorithms, some optimization techniques have been applied in structure design, particularly to optimize the configurations of foam-filled tubes. The 
maximum energy absorption and the minimum weight of foam-filled aluminum tubes under axial load were investigated [12]. Moreover, maximizing the specific energy absorption and minimizing the peak crash force using multi-objective optimization has been researched. For example, the maximum crush force efficiency (CFE) and the maximum specific energy absorption (SEA) of tapered circular thin-walled tubes using multi-objective crashworthiness optimization have been identified [13]. Moreover, different mathematical programming, such as genetic algorithms (GA) [14, 15] and particle swarm optimization (PSO) [16], has been used to seek optimal solutions.

In this paper, multi-objective optimization of tubular cylindrical aluminum tubes under axial impact loading is undertaken using the non-dominated sorting genetic algorithm II (NSGA II). Furthermore, this method is a fast and elitist GA [17]. The parameters of the structures, such as the inner diameter, outer diameter and thickness of the double tubes, were optimized. Previously, the crush behavior of tubes has been simulated in finite element software ABAQUS/Explicit. The results of the simulations were validated against the relevant experimental tests in the literature. The radial basis function (RBF) was used to construct the approximating design sub-problem. Finally, this research presents Pareto solution sets.

\section{NUMERICAL SIMULATION}

Finite element (FE) simulation is part of crashworthiness optimization. In this work, computer simulation of double circular tubes under quasi-static axial impact loading using the FE code with ABAQUS software was undertaken. The tubular circular tubes were placed between two rigid walls. Figure 1 shows all of the tubes fixed at the bottom with the other end impacted by a moving rigid wall with constant velocity of $0.9 \mathrm{~m} / \mathrm{s}$. Empty and aluminum foam-filled thin-walled double circular tubes $200 \mathrm{~mm}$ long (l) were considered. The variable design parameters of the tubes are the inner diameter $(d)$ $45 \mathrm{~mm}$, the outer diameter $2 d$, and the thickness $(t) 2.5 \mathrm{~mm}$.
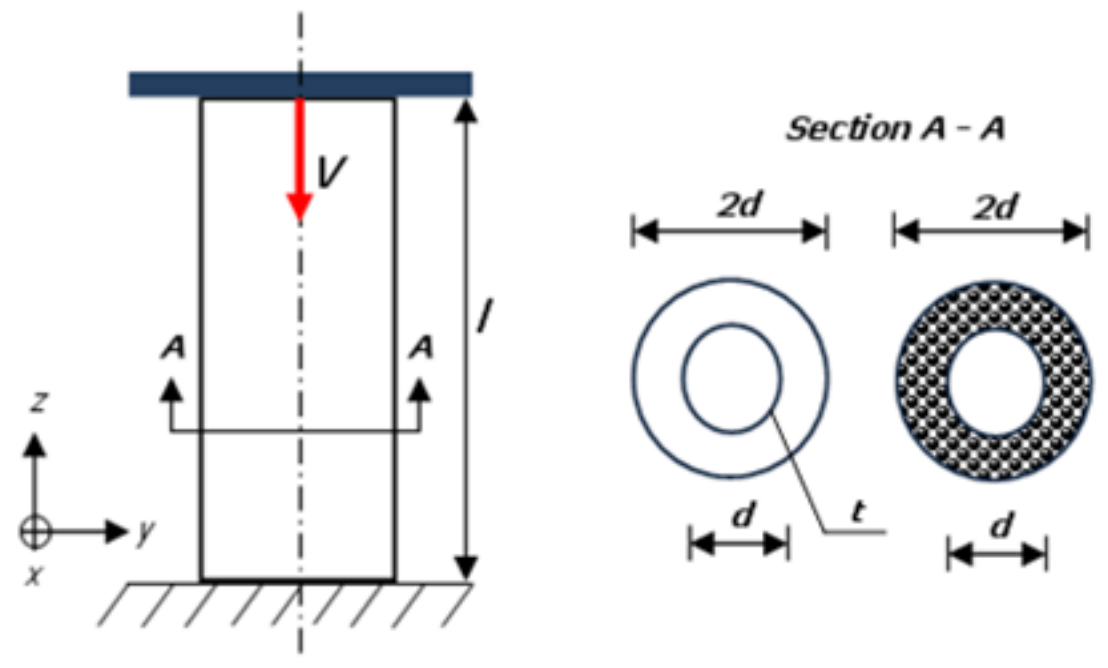

Figure 1. Dimensions, boundary, and loading condition of the aluminum foam-filled double tube.

The walls of the inner and outer tubes were made from aluminum alloy A6063 T6 with density $\rho=2700 \mathrm{~kg} / \mathrm{m}^{3}$, Young's modulus $E=60.2 \mathrm{GPa}$, Poisson's ratio $v=0.3$, initial yield stress $\sigma_{y}=184.4 \mathrm{MPa}$, and ultimate stress $\sigma_{u}=215.5 \mathrm{MPa}$ with 
engineering stress-strain, as in Figure 2. In addition, the aluminum foam filler was produced by liquid state processing using $\mathrm{TiH} 2$ as the foaming agent, giving average mechanical property values of nominal density $\rho_{f}=0.45 \mathrm{~g} / \mathrm{cm}^{3}$, Young's modulus $E=$ $625 \mathrm{MPa}$, compression strength $\sigma_{c}=9.74 \mathrm{MPa}$, and plateau stress $\sigma_{p}=8.12 \mathrm{MPa}$ [18].

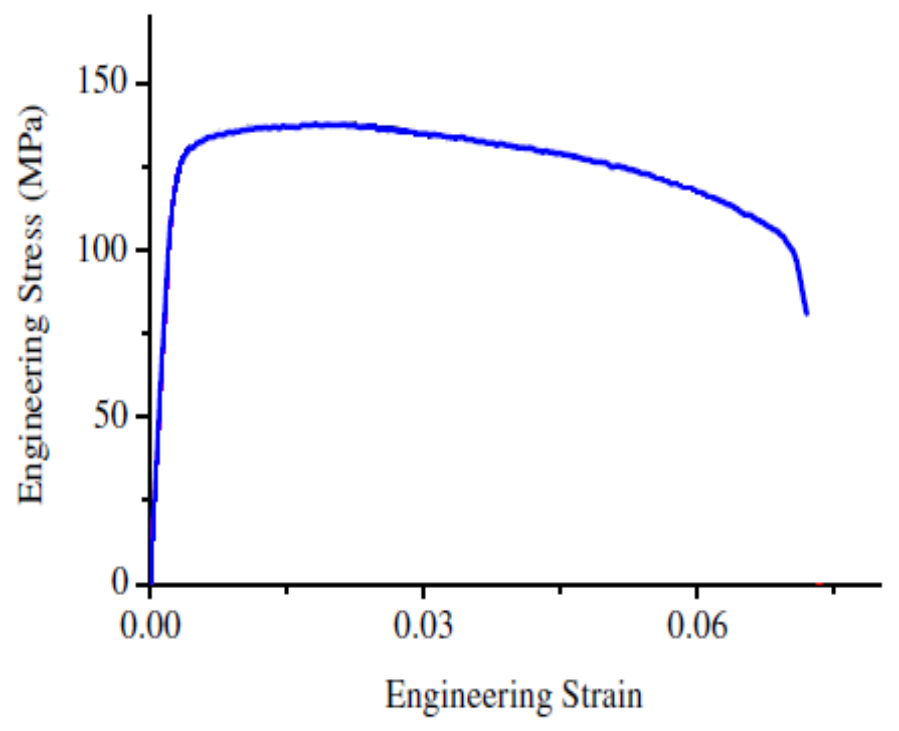

Figure 2. Engineering strain-stress curve of the A6063 T6 [18].

A maximum crash distance of $100 \mathrm{~mm}$ was assumed, representing a stroke efficiency of 0.5. Moreover, the rigid wall was defined in the $\mathrm{y}-\mathrm{z}$ plane and ABAQUS FE software was used to develop the FE models of the different cross-section double tubes in Figure 3. Four node-shell continuum elements, with five integration points along the thickness direction of the element modeled the thin wall structure. Furthermore, eight node continuum elements used the reduced integration technique to develop the foam. Based on a mesh convergence study, an element size of $5 \mathrm{~mm}$ was chosen for the shells and the foam [19].

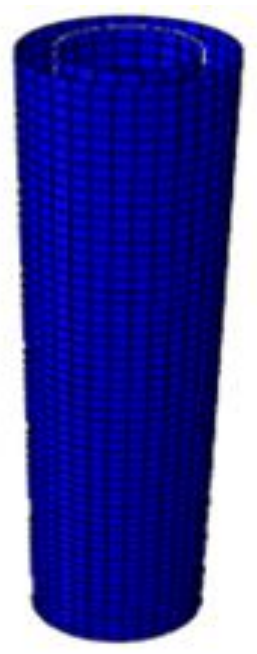

(a)

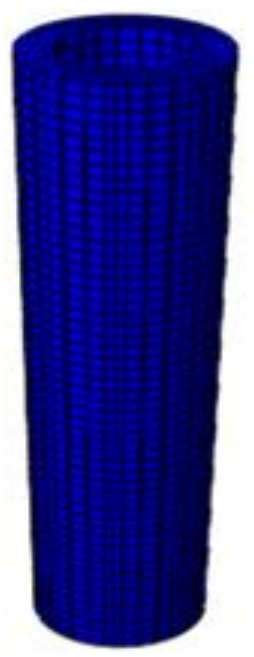

(b)

Figure 3. FE models of cylindrical double tubes (a) empty and (b) foam filled. 
To simulate contact between all components the "general contact algorithm" was used with the contact algorithm. As finite sliding penalty based contact algorithm with contact pairs and hard contact to model the contact between the tube walls with and without foam. The friction coefficient was set at 0.2 for all contact surfaces [19].

\section{VALIDATION}

The FE results and the experimental data in the literature were studied to ensure that the developed models are accurate in order to be explored for design optimization, particularly in the simulation of double-cylinder aluminum-foam tubes. The experiment [20] studied the deformation and energy absorption of empty, aluminum-foam singleand double-cylinder tubes under oblique impact and the result explained that double tubes have more crashworthiness capability to absorb energy than other structures. Figure 4 shows the correlation graph between the results of the experiment and the numerical simulation of aluminum-foam double-cylinder tubes with respect to displacement and crushing force. Table 1 shows the difference between the experiment and numerical simulation, which is similar to references [21-23]. From these results, it can be assumed that the developed FE models are competent for design optimization exploration.

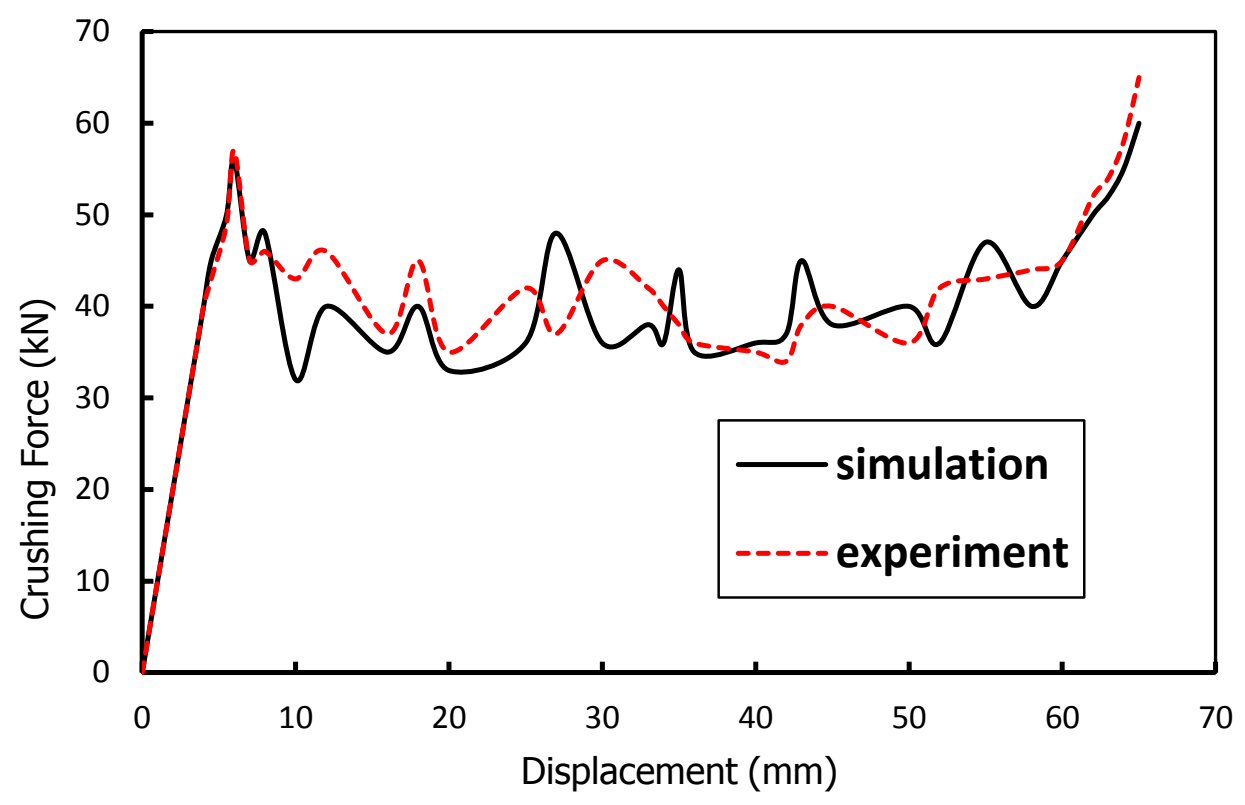

Figure 4. Comparison between (a) the experimental test [20] and (b) the numerical simulation.

Table 1. Difference between experimental test [20] and numerical simulation.

\begin{tabular}{cccc}
\hline Parameters & Experiment & Simulation & Error \% \\
\hline Crushing force $(\mathrm{kN})$ & 56.3 & 57.1 & 1.42 \\
Energy absorption $(\mathrm{J})$ & 2143 & 2140.8 & 0.11 \\
\hline
\end{tabular}




\section{CRASHWORTHINESS OPTIMIZATION}

$\mathrm{RBF}$ is a surrogate model that represents the relationships between the individual objective functions and the design variable vector. Given the design variable vector and the response values at $n$ arbitrary design (training) points, the RBF approximation of the response function $f^{\prime}(x)$ was derived from an FE simulation, as the following expression:

$$
f^{\prime}(x)=\sum_{i=1}^{n} \lambda_{i} \varnothing\left(\left\|x-x_{i}\right\|\right)
$$

where, $x$ is the vector of the normalized design (input) variables with $x_{i}$ representing the normalized coordinates of the $i_{\text {th }}$ training point, $\mathrm{ri}=|| x-x_{i}||=\sqrt{ }\left(\left(x-x_{i}\right)^{T}\left(x-x_{i}\right)\right)$, $\emptyset$ is a radial symmetric basis function, and $i=1$ is the unknown interpolation coefficient.

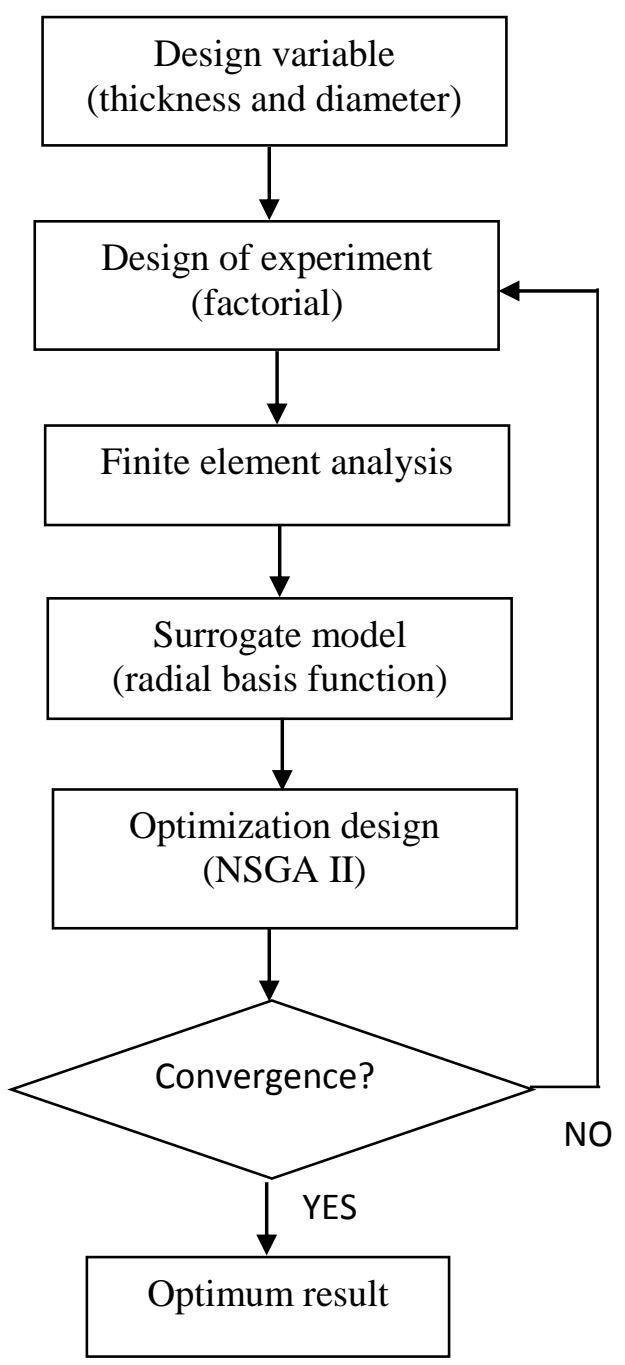

Figure 5. Flowchart of the multi-objective optimization of double cylindrical tubes 
The GA is a popular optimization tool, because it avoids the trapping capability of searching for an optimum in local optima. The non-dominated sorting GA (NSGA) is a more effective and efficient algorithm in ranking solutions, assigning ranking fitness, and benchmarking number problems. Figure 5 shows the implementation of multiobjective optimization for the empty and foam-filled double-cylinder tubes. The flow chart clarifies the whole crashworthiness multi-objective optimization using finite element analysis (FEA) and produces the code for RBF and NSGA II using MATLAB. However, NSGA II, based on a fast non-dominated sorting principle, was used herein to calculate the formulas for multi-objective optimization in Equation (2). Several researchers have investigated simultaneous optimization of two-criteria crashworthiness. This is a multi-objective optimization scheme. In general, the mathematics of multi-objectives can be expressed as:

$$
\left\{\begin{array}{c}
\operatorname{Min} F(x)=\left[f_{1}(x), f_{2}(x), \ldots, f_{n}(x)\right]^{T} \\
\text { s.t. } x \in R^{m} \text { and } x^{L} \leq x \leq x^{u} \\
g_{u}(x) \geq 0, u=1, \ldots, s \\
h_{v}(x)=0, v=1, \ldots, p
\end{array}\right.
$$

where, $x$ is the design variable vector, $n$ is the objective function number, $f_{n}(x)$ is the objective function of the objective, $x^{L}=\left(x_{1}^{L}, x^{L}, \ldots . x_{1}^{L}\right)$ denotes the lower bound, and $x^{U}$ $=\left(x_{1}^{U}, x_{2}^{U}, \ldots . x_{1}^{U}\right)$ the upper bound of the $m$ design variables, and $s$ and $p$ are the numbers of the unequal and equal constraints, respectively.

\section{RESULTS AND DISCUSSION}

In the quasi-static loading condition, the axial impact of empty and foam-filled aluminum double circular tubes was modeled. Figure 6 shows the different height reductions of empty and foam-filled circular tubes. At the same time, the collapse mode of the aluminum foam-filled tubes is higher than the empty double circular tubes due to the frictional interaction between the foam filler and the inner/outer tubes [21]. Similarly, the ability of the circular foam-filled tubes to absorb energy is greater than that of the empty tubes, as shown in Figure 7.

The optimization equations of the double tubes were derived by considering the parameters. The results were expected to determine the maximum SEA and the minimum peak crushing force (PCF). The optimization equation is shown below:

$$
\begin{gathered}
\operatorname{Min}\{-S E A(t, d), P C F(t, d)\} \\
\text { s.t. } 1.5 \mathrm{~mm} \leq t \leq 3 \mathrm{~mm} \\
20 \mathrm{~mm} \leq d \leq 25 \mathrm{~mm}
\end{gathered}
$$

$$
\begin{aligned}
& \text { SEA }(t, d)=-0.00584454+0.53921 t+0.66557 d-0.85593 t^{2}+1.34975 t d \\
& +0.67566 d^{2}-0.97651 t^{3}+2.75487 t^{2} d+0.08976 t d^{2}+0.09135 d^{3}+0.58934 t^{4} \\
& -0.93167 t d^{3}-1.89616 t^{2} d^{2}+0.07195 t^{3} d-0.24987 d^{4} \\
& \text { PCF }(t, d)=0.0348443+0.87295 t+0.92403 d-0.32943 t^{2}+1.78534 t d \\
& +0.94024 d^{2}-0.03453 t^{3}+2.87353 t^{2} d+0.09340 t d^{2}+0.08349 d^{3}+0.25564 t^{4} \\
& -0.74594 t d^{3}-1.03368 t^{2} d^{2}+0.08354 t^{3} d-0.389456 d^{4}
\end{aligned}
$$



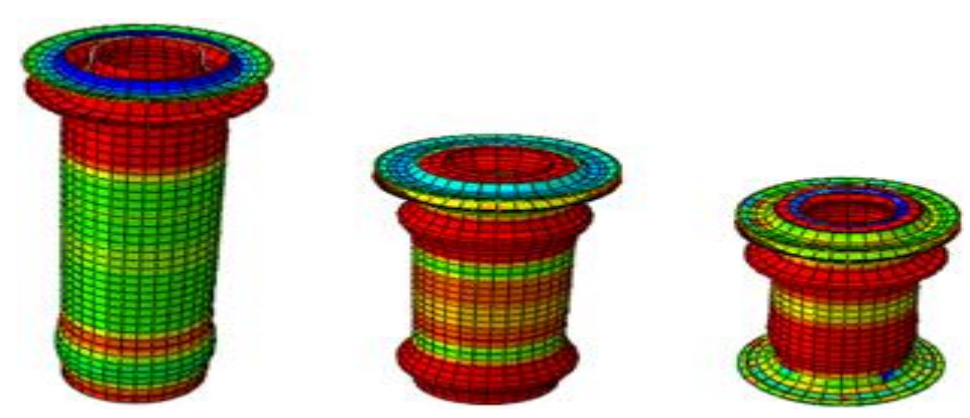

(a)
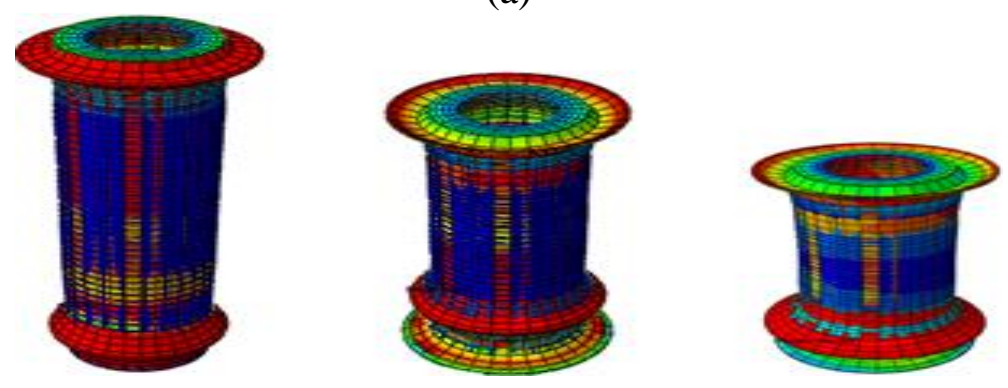

(b)

Figure 6. Deformation modes of (a) empty and (b) foam-filled circular tubes.

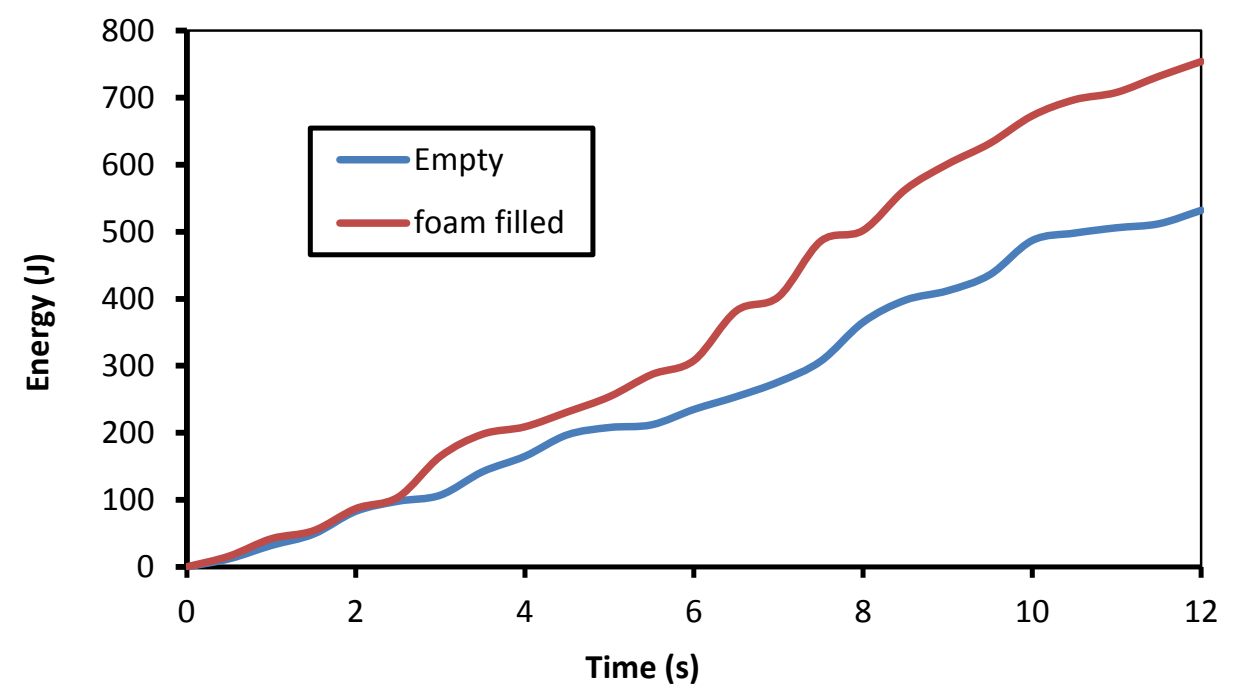

Figure 7. Energy vs time of the empty and foam-filled double circular tubes.

Figure 8 shows that the outcome of the circular point optimization represents the Pareto front solutions, which explains the trade-off between SEA and PCF. From Figure 8 it can be seen that the foam-filled structure has a lower PCF and more energy absorption capacity than the empty double tube, as in reference [22]. Table 2 shows the influence of the foam on the crashworthiness optimization results for the aluminum foam double tube. The maximum SEA value, and on the other side the minimum PCF value on axial impact, were investigated and the results shown in Table 2. 
Table 2. Ideal optimum objective function for the double tube under axial impact loading.

\begin{tabular}{cccccc}
\hline Double tube & $\begin{array}{c}\text { Objective } \\
\text { function }\end{array}$ & $t[\mathrm{~mm}]$ & $d[\mathrm{~mm}]$ & $\mathrm{SEA}[\mathrm{kJ} / \mathrm{kg}]$ & $\mathrm{PCF}[\mathrm{kN}]$ \\
\hline \multirow{2}{*}{ Empty } & SEA & 2.65 & 42.43 & $\mathbf{1 4 . 9 7}$ & 11.74 \\
& PCF & 2.64 & 40.67 & 4.07 & $\mathbf{2 . 5 6}$ \\
Foam-filled & SEA & 2.75 & 42.46 & $\mathbf{1 5 . 4 3}$ & 14.54 \\
& PCF & 2.19 & 40.15 & 4.83 & $\mathbf{3 . 6 7}$ \\
\hline
\end{tabular}

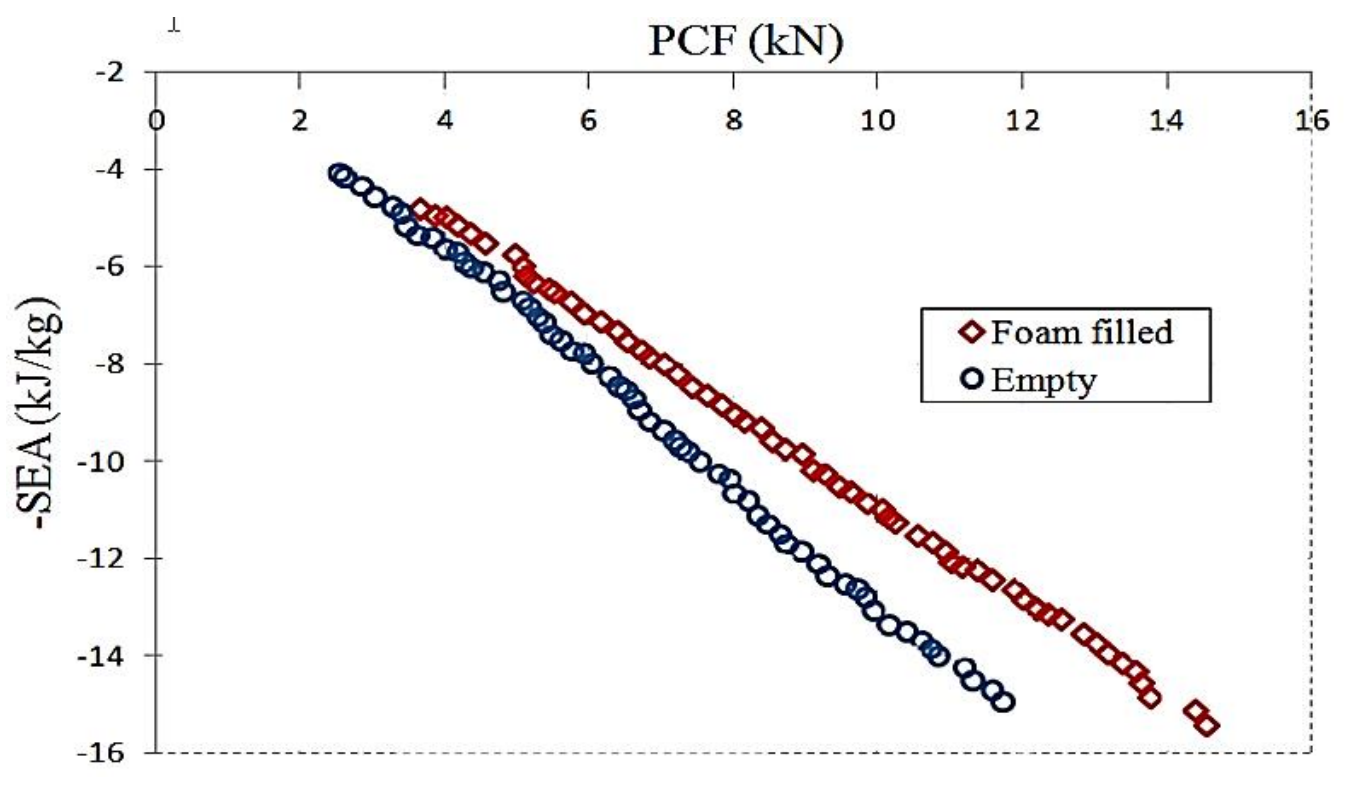

Figure 8. Pareto fronts of PCF vs SEA for the double cylindrical tubes.

\section{CONCLUSIONS}

This paper presented the model and the optimization of aluminum foam cylindrical double tubes under axial impact loading by considering two tube structures. The FE model predicted the crashworthiness parameters of the tubes with great accuracy. The percentage difference in PCF and energy absorption between the experimental tests and the simulation were $1.42 \%$ and $0.11 \%$. The multi-objective optimization equation was formulated to determine the maximum SEA and minimum PCF with different design variables, such as thickness and diameter of the tube walls. By using NSGA II, the optimum results showed that the crashworthiness capability of foam-filled double circular tubes $(\mathrm{SEA}=15.43 \mathrm{~kJ} / \mathrm{kg})$ was better than empty $(\mathrm{SEA}=4.97 \mathrm{~kJ} / \mathrm{kg})$. These results could be the foundation for designers to implement foam-filled double circular tubes, particularly as energy absorbers in automobile structures.

\section{ACKNOWLEDGEMENTS}

The authors would like to thanks Universiti Kebangsaan Malaysia for providing the financial support and laboratory facilities. 


\section{REFERENCES}

[1] Lu G, Yu T. Energy absorption of structures and materials: Elsevier; 2003.

[2] J ones N. Structural impact: Cambridge university press; 2011.

[3] Reid SR. Plastic deformation mechanisms in axially compressed metal tubes used as impact energy absorbers. International Journal of Mechanical Sciences. 1993;35:1035-52.

[4] Alghamdi AAA. Collapsible impact energy absorbers: an overview. ThinWalled Structures. 2001;39:189-213.

[5] Hanssen AG, Langseth M, Hopperstad OS. Static crushing of square aluminium extrusions with aluminium foam filler. International Journal of Mechanical Sciences. 1999;41:967-93.

[6] Hanssen A, Langseth M, Hopperstad O. Axial crushing of aluminium columns with aluminium foam filler. Seventh International Symposium on Structural Failure and Plasticity; 2000. p. 4-6.

[7] Hanssen AG, Langseth M, Hopperstad OS. Static and dynamic crushing of circular aluminium extrusions with aluminium foam filler. International Journal of Impact Engineering. 2000;24:475-507.

[8] Hanssen AG, Langseth M, Hopperstad OS. Optimum design for energy absorption of square aluminium columns with aluminium foam filler. International Journal of Mechanical Sciences. 2001;43:153-76.

[9] Santosa SP, Wierzbicki T, Hanssen AG, Langseth M. Experimental and numerical studies of foam-filled sections. International Journal of Impact Engineering. 2000;24:509-34.

[10] Seitzberger M, Rammerstorfer FG, Gradinger R, Degischer HP, Blaimschein M, Walch C. Experimental studies on the quasi-static axial crushing of steel columns filled with aluminium foam. International Journal of Solids and Structures. 2000;37:4125-47.

[11] Yuen SCK, Nurick G, Starke R. The energy absorption characteristics of doublecell tubular profiles. Latin American Journal of Solids and Structures, an ABCM Journal. 2008;5:289-317.

[12] Zarei HR, Kröger M. Optimization of the foam-filled aluminum tubes for crush box application. Thin-Walled Structures. 2008;46:214-21.

[13] Acar E, Guler MA, Gerçeker B, Cerit ME, Bayram B. Multi-objective crashworthiness optimization of tapered thin-walled tubes with axisymmetric indentations. Thin-Walled Structures. 2011;49:94-105.

[14] Nariman-zadeh N, Darvizeh A, Jamali A. Pareto optimization of energy absorption of square aluminium columns using multi-objective genetic algorithms. Proceedings of the Institution of Mechanical Engineers, Part B: Journal of Engineering Manufacture. 2006;220:213-24.

[15] Hou S, Li Q, Long S, Yang X, Li W. Crashworthiness design for foam filled thin-wall structures. Materials \& Design. 2009;30:2024-32.

[16] Sun G, Li G, Stone M, Li Q. A two-stage multi-fidelity optimization procedure for honeycomb-type cellular materials. Computational Materials Science. 2010;49:500-11.

[17] Deb K. Multi-objective optimization using evolutionary algorithms: John Wiley \& Sons; 2001.

[18] Guo LW, Yu JL. Bending behavior of aluminum foam-filled double cylindrical tubes. Acta Mechanical. 2011;222:233-44. 
[19] Guo L, Yu J. Dynamic bending response of double cylindrical tubes filled with aluminum foam. International Journal of Impact Engineering. 2011;38:85-94.

[20] Li Z, Yu J, Guo L. Deformation and energy absorption of aluminum foam-filled tubes subjected to oblique loading. International Journal of Mechanical Sciences. 2012;54:48-56.

[21] Djamaluddin F, Abdullah S, Ariffin AK, Nopiah ZM. Optimization of foamfilled double circular tubes under axial and oblique impact loading conditions. Thin-Walled Structures. 2015;87:1-11.

[22] Djamaluddin F, Abdullah S, Ariffin AK, Nopiah ZM. Multi objective optimization of foam-filled tubular circular tubes for quasi-static and dynamic responses. Latin American Journal of Solids and Structures, an ABCM Journal. 2014;12.

[23] Djamaluddin F, Abdullah S, Arrifin AK, Nopiah ZM. Multi-Objective optimization of aluminum foam double tube subjected to oblique impact loading for automobile bumper beam. Applied Mechanics and Materials. 2014;663:93-7. 